\title{
Constrained Citizens? Ideological Structure and Conflict Extension in the US Electorate, 1980-2016
}

\author{
Christopher Hare \\ University of California Davis, Davis, California, USA \\ Corresponding author. Email: cdhare@ucdavis.edu
}

(Received 2 September 2020; revised 27 June 2021; accepted 3 August 2021; first published online 16 December 2021)

\begin{abstract}
Past the half-century mark of Converse's (1964) field-defining essay, the nature of political ideology in the mass public and how it has changed in response to partisan polarization remains enigmatic. To test the ideological structure of US public opinion, I develop and implement a Bayesian dynamic ordinal item response theory model. In contrast to static scaling procedures, this method allows for changes in the mappings between issue attitudes and the underlying ideological dimension over time. The results indicate that over the last forty years, mass attitudes on a range of long-standing policy controversies better fit a unidimensional ideological structure. As among elites, the left-right dimension has come to encompass a wide range of policy, partisan, and value divides in the mass public. Further, these trends hold for voters at all levels of political sophistication. Widespread conflict extension appears to be a defining feature of mass polarization in contemporary US politics.
\end{abstract}

Keywords: mass ideology; attitude constraint; political polarization; conflict extension; ideal-point estimation

There is no such thing as a single-issue struggle, because we do not live single-issue lives. (Lorde 1984)

Even the casual observer of US society must take note of the speed and ease with which nonpolitical matters become embroiled in political conflict. Familiar partisan and ideological divisions seem to creep into everything: from dating apps to pandemic behavior; decisions about where to live and what to eat; and deeper value, religious, and moral commitments. ${ }^{1}$ The primacy of left-right conflict calls out for a reconsideration of the nature and meaning of ideological constraint in the US mass public.

Indeed, scholars have come to recognize that political polarization should be understood not simply by the depth of policy differences between political factions, but also by their breadth-the sheer number and variety of issues or controversies that define partisan-ideological conflict (see, for example, Baldassarri and Gelman 2008; DellaPosta forthcoming). Layman and Carsey (2002a, 2002b) termed this phenomenon "conflict extension," contrasting it with "conflict displacement." Under conflict displacement, new issues arise to replace the primary dimension of competition (see, for example, Miller and Schofield 2003). With conflict extension, new divisions are instead added to existing lines of political conflict. For example, voters who previously disagreed about universal healthcare and the estate tax would also disagree about abortion and race relations.

\footnotetext{
${ }^{1}$ See, for instance, Huber and Malhotra (2017), Clinton et al. (2021), Endres and Panagopoulos (2017), Brown and Enos (forthcoming), and Goren, Smith, and Motta (forthcoming).

(c) The Author(s), 2021. Published by Cambridge University Press. This is an Open Access article, distributed under the terms of the Creative Commons Attribution licence (http://creativecommons.org/licenses/by/4.0/), which permits unrestricted re-use, distribution and reproduction, provided the original article is properly cited.
} 
The level of conflict extension in the mass public speaks to a fundamental trade-off in a pluralistic democracy. On the one hand, the presence of reinforcing policy cleavages-particularly those involving emotional, "high heat" social and cultural matters-changes the tenor of democratic deliberation (Hetherington 2009). Political competition becomes Manichaean: less transactional and more messianic. This environment fosters partisan-ideological antipathy, resistance to compromise, and other manifestations of affective polarization (see, for example, Enders and Lupton forthcoming). However, scholars have also long bemoaned the electorate's inability to organize their political preferences in ideological terms (Converse 1964; Kinder and Kalmoe 2017). Ideology fosters democratic accountability by providing a heuristic, enabling elites to efficiently communicate with voters and voters to make choices on the basis of low-dimensional ideological proximity (Hinich and Munger 1994; Stoetzer 2019). Conflict extension serves to facilitate ideological thinking in the mass electorate by more clearly connecting policy positions and defining "what goes with what" across a wide range of issues.

This article examines conflict extension and ideological structure in the US mass public over the last forty years. It does so by measuring the degree to which American voters' attitudes on a range of policy issues have become constrained along a common, latent left-right ideological dimension. The key innovation in this article is its use of a dynamic measurement model that explicitly models changes in the mappings between individual issue attitudes and a latent organizing ideological dimension over time. This captures processes such as issue evolution (where issues become more or less "ideological" as a consequence of changes in the political environment) (Carmines and Stimson 1989) alongside left-right shifts in public opinion on controversies such as lesbian, gay, bisexual, trans, and queer (LGBTQ) rights. This not only provides more credibly comparable measures of voters' ideological positions across time, but also allows us to identify which issues load onto the latent conflict dimension, how strongly, and how these loadings evolve. ${ }^{2}$

Applying this measurement strategy to repeated cross-sectional survey data from the American National Election Study (ANES) Time Series studies between 1980 and 2016 yields a series of important substantive findings. First, there has been a consistent trend toward greater conflict extension in Americans' policy attitudes over the last forty years. Specifically, social/cultural issue attitudes and core value dispositions have been increasingly absorbed into the primary left-right conflict dimension, supplementing rather than displacing economic policy preferences and values on this dimension. In addition, citizens with low and moderate levels of political sophistication are catching up to their highly sophisticated counterparts in terms of ideological constraint. These results provide a more nuanced account of mass political polarization-one where partisan conflict has become more widespread and intense by encompassing a larger, overlapping set of policy disagreements and value differences.

\section{Ideological Structure in US Public Opinion}

Across time and space, political elites compete over a single left-right ideological dimension. This dimension of conflict has become especially pronounced in the United States over recent decades. Members of Congress (Poole and Rosenthal 2007), state legislators (Shor and McCarty 2011), campaign contributors (Bonica 2014), and party activists (Lupton, Myers, and Thornton 2015) all take policy stances that conform to a left-right continuum. Although citizens must grapple

\footnotetext{
${ }^{2}$ However, researchers should be cautious when making intertemporal and/or cardinal comparisons with latent estimates (see, for example, Ho and Quinn 2010, 844-7). Nonetheless, the issue parameters and respondent ideal points can serve as a valuable resource in studies of public opinion and voting behavior beyond their applications in this article. For instance, the issue and ideal-point rank orders could be used to compare electoral subgroups, assess ideological movement (especially more abrupt shifts) among voters, or test the effects of particular events on mass ideological constraint (for further discussion about conducting statistical tests with dynamic measurement models, see Caughey and Warshaw 2015; Fariss 2014; Martin and Quinn 2002; Reuning, Kenwick, and Fariss 2019).
} 
with a unidimensional choice set presented by highly constrained elites, to what extent do voters themselves hold attitudes that fit the same left-right structure?

The scholarly dispute over the degree to which Americans are "ideologically innocent" was launched by Converse's (1964) famous essay. Converse's results unambiguously supported the proposition that only a small proportion of Americans can be characterized as ideological, with the rest lacking a meaningful understanding of ideological terms and holding unstable policy preferences across time. Survey respondents' attitudes also exhibited negligible levels of constraint or systematic organization, namely, the observed correlations between pairs of respondents' issue attitudes were extremely low, rarely greater than 0.3 , and often negative.

Popkin $(2006,233)$ writes that Converse's essay "is at one and the same time a milestone and a millstone." Indeed, in the half-century since its publication, it continues to define the subfield (see, for example, Kinder and Kalmoe 2017), even as its conclusions have been challenged on multiple fronts. For one, many scholars have argued that attitudinal constraint is tied to the amount and clarity of ideological conflict present in the political environment. Indeed, later studies found considerably higher intercorrelations between issue attitudes, and attributed this result to a shift from the relatively ideologically tranquil environment of the 1950s to the more tumultuous period of the 1960s (Nie, Verba, and Petrocik 1979). Greater ideological conflict on salient issues like civil rights and Vietnam seemed to clarify the ideological connections between policy issues for voters.

According to this view, the political environment and the nature of the two-party system promote ideological constraint in the mass public by packaging and communicating competing "menus" of policy positions (Sniderman and Bullock 2004; Stimson 2015). As Sniderman (2017, 43) argues: "[I]t has tacitly been supposed that citizens must organize ideas relying on their own resources. That is not so. The ecology of the party system affords partisans an opportunity to make ideologically coherent choices without exceptional effort on their part." Parties are certainly not the only political actors involved in defining ideological agendas (see, for example, Noel 2013), but they are the most effective channel for communicating ideological distinctions to the electorate.

Contemporary elite-level polarization provides such a clarifying environment for voters. Over recent decades, party leaders, activists, candidates, and other political elites have increasingly taken ideologically consistent positions on a range of economic and noneconomic policy issues. This has served to promote voters' awareness of ideological differences between the parties andaccording to elite-centered perspectives-driven partisan sorting (that is, the alignment of partisanship and ideology) in the mass electorate (Abramowitz and Saunders 1998; Enders and Armaly 2019; Levendusky 2009). Several mechanisms-generational replacement, partisan change, and ideological conversion-each contribute to a feedback loop that produces sorting, creates more homogeneous party coalitions, and better signals to voters the connection between partisanship and issues (Carsey and Layman 2006; Highton and Kam 2011; Stoker and Jennings 2008). Comparative work demonstrates that these patterns also work in reverse, for instance, elite depolarization (as began in Britain during the 1990s) produces lower rates of partisan sorting in the mass electorate (Adams, Green, and Milazzo 2012).

If political context conditions mass constraint, we should expect to find that politically aware citizens hold more ideologically constrained preferences. Indeed, this relationship is one of the more robust findings in the study of political behavior. Beginning with Converse (1964), scholars have demonstrated that citizens with higher levels of education, political knowledge, and political engagement possess better-constrained attitude structures that connect issue positions across policy domains (Jacoby 1991; Lupton, Myers, and Thornton 2015; Stimson 1975). Recognition of the parties' relative left-right positions-distinctions that have been better clarified in recent decades-is an especially important predictor of attitude stability and ideological consistency (Freeder, Lenz, and Turney 2019; Palfrey and Poole 1987). Hence, while aggregate studies are useful in assessing the ideological structure of policy attitudes in the electorate as a whole, such an 
approach can also mask substantial heterogeneity present under the surface of public opinion. We should expect to find higher levels of attitudinal constraint among politically sophisticated citizens than their less sophisticated counterparts, even if contemporary polarization has served to close the gap by providing clearer ideological cues (Levendusky 2010; Zingher and Flynn 2019).

There have also been sustained methodological challenges to Converse's results and, more generally, the use of issue intercorrelations to measure ideological constraint. Single-issue scales are especially vulnerable to measurement error (for example, due to vague or poorly worded survey instruments), and this downwardly biases observed levels of attitudinal stability and constraint (Achen 1975). Aggregating multiple-issue questions-either through simple additive scales or more sophisticated measurement models-serves to correct for measurement error present in individual survey responses (Ansolabehere, Rodden, and Snyder 2008; Jackson 1983). Consequently, more sophisticated measurement models of public opinion have tended to produce more optimistic conclusions about the degree of ideological structure underlying mass policy preferences (Freeze and Montgomery 2016; Shor and Rogowski 2018). ${ }^{3}$

Finally, scholars have become increasingly appreciative of the role that core values and beliefs can serve in constraining citizens' political attitudes. The idea that core values (or "crowning postures") could serve to link policy preferences along overarching principles also finds its roots in Converse (1964, 210-11) and has been empirically demonstrated in subsequent work (Feldman 2003). Since core values and value hierarchies are universal components of human behavior, they also have the potential to provide accessible gateways to ideological structure. Goren (2013), for instance, shows that both politically sophisticated and unsophisticated citizens derive specific issue attitudes from basic principles concerning the role of government in general policy domains (see also Goren, Smith, and Motta forthcoming).

The constraining effect of core values is contingent, of course, on the degree to which value and partisan-ideological conflict overlap in the political environment. This is an alignment that has indeed grown more pronounced in recent years (Barker and Tinnick 2006; Jacoby 2014), fostered by the rise of symbolic, value-laden "easy" issues (Carmines and Stimson 1980) on the political agenda and the use of elite rhetoric that connects core values and party positions (Clifford and Jerit 2013; Hetherington and Weiler 2009; Lupton, Smallpage, and Enders 2020). ${ }^{4}$ Partisans should also be more likely to accept their party's issue policy positions if they believe they share an underlying set of core values and principles, especially when those positions are presented in polarized terms (Druckman, Peterson, and Slothuus 2013).

\section{Conflict Extension in the Mass Electorate}

We should expect to find higher levels of mass ideological constraint when political parties and other elite actors are simultaneously polarized on a large number of policy issues and core values. Indeed, while most studies of mass polarization focus on changes in the ideological positions of citizens over time, this type of analysis tells only part of the story. Polarization also involves changes in the meaning of the left-right dimension that defines and drives political conflict.

This aspect of polarization presents a deep normative trade-off. As political competition incorporates a wider set of policy and non-policy cleavages, citizens have access to a larger number of pathways to ideological constraint. Political choices are clearer and elections become more meaningful. Moreover, when citizens' policy attitudes conform to the same dimension over which candidates and parties compete, mass-elite representational linkages become more direct. However,

\footnotetext{
${ }^{3}$ Jessee (2012), for instance, finds that a unidimensional item response theory (IRT) model correctly classifies about 80 per cent of respondents' choices on a set of congressional roll-call votes.

${ }^{4}$ Specifically, when value-based and other non-political cleavages overlap with partisan-ideological differences, they provide citizens with schematic (Hamill, Lodge, and Blake 1985; Thorisdottir et al. 2007) and affective (Brady and Sniderman 1985; Davis, Klar, and Weber 2019) heuristics to better understand the structure of political competition.
} 
when cross-cutting conflicts begin to overlap, the resulting "meta-cleavage" also strains democratic deliberation and consensus in a pluralistic society (Habermas 1996; Hetherington 2009). Berelson $(1952,328)$ warned of the risks associated with "total politics":

[E]ven at the height of a presidential campaign there are sizable attitudinal minorities within each party and each social group on political issues, and thus sizable attitudinal agreements across party and group lines. Such overlappings link various groups together and prevent their further estrangement. All of this means that democratic politics in this country is happily not total politics-a situation where politics is the single or central selector and rejector, where other social differences are drawn on top of political lines.

The theory of "conflict extension" (Layman and Carsey 2002a) provides a framework to explain how a diverse set of issues can be absorbed into a single dimension of political competition. Conflict extension places itself in contrast to "conflict displacement," which posits that as new controversies or buried partisan cross-cutting divisions gain salience, they supplant the dominant dimension of political conflict (Miller and Schofield 2003; Sundquist 1983). Partisan-ideological conflict is reorganized around the new cleavage-as was the case with the issue of slavery in the lead-up to the American Civil War-while the parties depolarize on the displaced conflict.

According to the conflict extension perspective, new cleavages need not replace existing ones; rather, parties can simultaneously polarize across multiple policy domains. This process is driven by policy-focused party activists and engaged issue publics, both of whom push the parties toward extreme positions on their principal issue(s) while personally converting on issues they find less salient (see also Bawn et al. 2012; Carsey and Layman 2006; Layman et al. 2010). Although there are some constraints on the universe of feasible configurations of policy positions that party coalitions can realistically adopt (see, for example, Noel 2013; O’Brian forthcoming; Schickler 2016), parties nonetheless enjoy wide latitude in bundling a set of overlapping conflicts into stable ideological configurations, as the nature of polarization in contemporary US politics has demonstrated.

The process of conflict extension tends to reinforce itself through a positive feedback loop. Overlapping conflicts provide multiple pathways to the same partisan-ideological configuration. Better-sorted voters, in turn, further clarify party differences. Each process feeds into the other, and partisan competition engulfs both a wider set of conflicts and a larger segment of the electorate. Consequently, when the same political opponents repeatedly clash over emotional issues and fundamental values with messianic zeal, it becomes easier to view the other side as evil rather than merely incorrect (Hunter 1991). It is not surprising that compromise becomes more elusive and acrimony more widespread in such an environment (Davis 2019; Iyengar and Westwood 2015; Orr and Huber 2020; Rogowski and Sutherland 2016).

While conflict extension has been most pronounced at the elite level, to date, there has been only limited evidence that voters are also bringing their attitudes on economic, social, and racial issues into greater unidimensional alignment (Layman and Carsey 2002a, Layman and Carsey 2002b). This article offers an updated assessment of mass constraint by developing a method that directly measures changes in the mappings between specific issues and a latent ideological dimension in the mass electorate, and applying it to survey data over the last forty years. This provides a novel way to model the dynamics of ideological constraint and conflict extension among voters.

\section{The Bayesian Dynamic Ordinal Item Response Theory Model}

To address this question, I develop an adaptation of the two-parameter item response theory (IRT) model designed specifically to measure changes in the level of ideological constraint and 
conflict extension in the US electorate. The two-parameter IRT model has become a popular alternative to factor analysis in studies of mass ideology over the last decade (see, for instance, Caughey and Warshaw 2015; Hill and Tausanovitch 2015; Jessee 2012; Treier and Hillygus 2009; Zhou 2019). IRT models have a long lineage in psychological and educational testing, where they are used to derive estimates of subjects' latent ability and information about the test items. Specifically, the two-parameter IRT model estimates two item-specific quantities: the difficulty parameter (which indicates the difficulty of the test item) and the discrimination parameter (which measures how well the test item distinguishes correct and incorrect answers on the basis of subjects' estimated ability).

The IRT model has been adapted in political science by substituting both ideology for ability and issue positions (measured through indicators such as roll-call votes and public opinion survey questions) for test items. For instance, an issue that is only weakly related to the ideological dimension would have a discrimination parameter with a low (absolute) value, while an issue that is closely connected to the ideological divide (for example, private versus government healthcare) would have a discrimination parameter with a high (absolute) value. The sign on the discrimination parameter simply indicates whether higher scores on the ideological dimension correspond to an increase or decrease in the probability of answering with an affirmative response (for example, a "yea" roll-call vote). Likewise, the difficulty parameter provides information about how conservative or liberal a respondent must be in order to be classified as supporting a given policy position. The ability parameter (which represents subjects' latent ability in the field being tested in traditional IRT modeling) indicates the estimated ideological position of each respondent.

The article adopts a Bayesian implementation of the two-parameter IRT model (Martin and Quinn 2002) based on the following considerations. First, the Bayesian framework offers a flexible approach to estimate latent quantities, especially when those quantities are dynamic. In our context, we wish to estimate survey respondents in a shared ideological space (which provides some degree of comparability between ideal points), but we also recognize that the mappings between issues and latent ideology evolve over time. The Bayesian implementation uses random-walk priors to facilitate estimation of the dynamic item parameters (that is, the mappings between issue attitudes and positions on the latent dimension). This hierarchical structure ensures that the issue mappings smoothly evolve over time, as estimates from the previous survey year serve as prior information that enters into the subsequent period. This strategy produces more efficient estimates of the item parameters than static methods (see, for example, Reuning, Kenwick, and Fariss 2019, 508).

The Bayesian IRT model also allows uncertainty to propagate throughout the model. This uncertainty is automatically reflected in the posterior estimates, and the resulting uncertainty bounds are readily interpretable in terms of probabilities. Finally, this implementation accommodates the ordinal nature of most public opinion survey data (for example, Likert and issue scales). ${ }^{5}$ Adding these components together gives us the Bayesian dynamic ordinal IRT (DO-IRT) model. ${ }^{6}$

To more formally develop this model, let $z_{i j}$ represent the choice by respondent $i(i=1, \ldots, n)$ on issue $j(j=1, \ldots, p)$. Each issue $j$ provides a total of $C$ response categories $(c=1, \ldots, C)$. In the standard two-parameter IRT setup, the latent response $z_{i j}^{*}$ is modeled using Equation 1 . The item difficulty parameter $\left(\alpha_{j c}\right)$ provides the $C-1$ cut points between the response categories, while the item discrimination parameter $\left(\alpha_{j c}\right)$ represents the loading of issue $j$ onto the latent ideological

\footnotetext{
${ }^{5}$ For a detailed treatment of the ordinal IRT model, see Quinn (2004). In the psychometric literature, this model is often referred to as the graded response model (Samejima 1997).

${ }^{6}$ This terminology and abbreviation are also used by Fariss (2014), who implements a similar model to study changes in human rights practices by countries over time. The two models differ in that both item parameters (the difficulty and discrimination parameters) are dynamic in this article's implementation.
} 
dimension. The respondent ideal points are denoted by $\theta_{i}$, and $\beta_{j}$ is the item discrimination parameter. The error term, $\varepsilon_{i j}$, is assumed to be normally distributed and the errors to be independent and identically distributed:

$$
z_{i j}^{*}=\alpha_{j c}-\beta_{j} \theta_{i}+\varepsilon_{i j}
$$

The probability of respondent $i$ providing response $c(c=1, \ldots, C)$ to issue $j$ at time $t$ is modeled using the standard normal cumulative distribution function, shown in Equations $2-4$. As in standard ordered logit/probit, the cut points $\left(\alpha_{j c}\right)$ are ordered consecutively:

$$
\begin{gathered}
\pi\left[z_{i j}=1\right]=\Phi\left(\alpha_{j 1}-\beta_{j} \theta_{i}\right) \\
\pi\left[z_{i j}=c\right]=\Phi\left(\alpha_{j c}-\beta_{j} \theta_{i}\right)-\Phi\left(\alpha_{j(c-1)}-\beta_{j} \theta_{i}\right)
\end{gathered}
$$

and

$$
\pi\left[z_{i j}=C\right]=1-\Phi\left(\alpha_{j(C-1)}-\beta_{j} \theta_{i}\right)
$$

To examine changes in the ideological structure of US public opinion over time, I add a dynamic component to this model. Specifically, I index the item parameters $\alpha_{j}$ (the issue difficulty parameter) and $\beta_{j}$ (the issue discrimination parameter) by time $t(t=1, \ldots, T)$. The respondent ideal points $\left(\theta_{i}\right)$ are not indexed by $t$ since no respondent participates in more than one survey. Hence, in this model, the probability of respondent $i(i=1, \ldots, N)$ choosing response category $c(c=1, \ldots, C)$ for item $j(j=1, \ldots, q)$ is provided in Equations 5-7:

$$
\begin{gathered}
\pi\left[z_{i j t}=1\right]=\Phi\left(\alpha_{j 1 t}-\beta_{j t} \theta_{i}\right) \\
\pi\left[z_{i j t}=c\right]=\Phi\left(\alpha_{j c t}-\beta_{j t} \theta_{i}\right)-\Phi\left(\alpha_{j(c-1) t}-\beta_{j t} \theta_{i}\right)
\end{gathered}
$$

and

$$
\pi\left[z_{i j t}=C\right]=1-\Phi\left(\alpha_{j(C-1) t}-\beta_{j t} \theta_{i}\right)
$$

Indexing the item parameters by $t$ allows for changes in the ways issues map onto the underlying ideological dimension over time. Changes in the discrimination parameter $\beta_{j t}$, for instance, signal whether issues have become more or less strongly linked to the ideological dimension. In this model, normal priors are used for $\theta_{i}, \beta_{j t}$, and $\alpha_{j c t}$, with diffuse gamma priors placed on the precision terms of the time-varying item parameters. ${ }^{7}$ At timet $>1$, the priors for $\alpha_{j c t}$ and $\beta_{j t}$ are centered at the value of those parameters at $t-1$. The use of "normal-walk priors" in dynamic spatial voting models is adopted from Martin and Quinn (2002) and intuitively appealing: our best estimate of the value of $\alpha_{j c t}$ and $\beta_{j t}$ is its value at the previous time point. Permitting the meaning of the recovered ideological dimension to smoothly evolve places the model in line with path-breaking dynamic measurement methods in political science, such as Poole and Rosenthal's (2007) DW-NOMINATE procedure and Martin and Quinn (2002) scores of

\footnotetext{
${ }^{7}$ Precision is the inverse of variance.
} 
Supreme Court justice ideology. The approach here is simply to switch which parameters vary over time (those associated with the items rather than the legislator/voter ideal points). ${ }^{8}$

In sum, the Bayesian DO-IRT model provides an appropriate measurement method to study changes in the meaning of the ideological dimension underlying voters' issue attitudes. Specifically, it accounts for the ordinal nature of survey responses, estimates uncertainty bounds for the latent variables, and allows the mappings between issues onto the ideological dimension to evolve across survey years. ${ }^{9}$ The results from this model allow for a richer understanding of the nature of mass polarization in the US electorate in two ways. First, the discrimination parameters indicate the degree to which citizens' policy attitudes fit a unidimensional ideological structure. This provides information about the number and types of policy disputes encompassed by a single dimension of ideological conflict. Secondly, a dynamic measurement model produces ideological scores for survey respondents that are more directly comparable over this period because it does not assume that the issue mappings are static. Policy controversies can become more or less ideological over time, while shifts in public opinion on other issues (for example, LGBTQ rights) mean that a "liberal" response to a particular survey item in 2016 might indicate something quite different than the same response given in 1988. I empirically demonstrate this in the following.

\section{The Growth in Mass Ideological Constraint, 1980-2016}

In this section, I test the theory of conflict extension in the mass electorate by assessing changes in the level of unidimensional ideological constraint in voters' policy attitudes over the last forty years. Specifically, I examine the loading of fifteen political issues onto a single latent ideological dimension among respondents from the 1980 through 2016 ANES. These issues include: traditional New Deal economic and social welfare policies; more postmaterialist concerns, such as environmental protection; social/cultural controversies involving abortion, LGBTQ rights, and gun control; and issues that tap into racial attitudes, such as aid to black people and immigration. ${ }^{10}$ I delete respondents who provide responses to less than three survey items, leaving 24,059 respondents in the analysis. ${ }^{11}$

I begin by analyzing the issue discrimination parameters over the period between 1980 and 2016. Figure 1 plots the means and 95 per cent credible intervals of the posterior distributions of the discrimination parameters for each of the fifteen issues. Recall that larger discrimination parameters indicate that the issue loads more strongly onto the latent dimension. ${ }^{12}$

Consistent with the theory of conflict extension, none of the fifteen issues have become less attached to the underlying ideological dimension during this period. Quite the opposite, we see meaningful increases in the discrimination parameters of the abortion, environment-jobs trade-off, gun control, government-private health insurance, immigration, and liberal-conservative identification items. The growth in constraint on issues such as abortion, environmental

\footnotetext{
${ }^{8}$ In DW-NOMINATE and standard dynamic IRT models, the legislators or voters both serve as bridges and can move positions in the latent ideological space, while the roll calls or issues on which they vote have unique parameters specific to a single time point. The implementation of the DO-IRT model developed here exactly reverses this setup.

${ }^{9}$ Posterior samples are collected by running three chains for 3,000 iterations, discarding the first 2,000 iterations, and thinning the remaining iterations by 5 . The unimodality of the posterior distributions and the Gelman-Rubin diagnostic indicate convergence. Additional details about model identification and priors are provided in the supplementary materials (available online).

${ }^{10}$ Naturally, many of these issues fall into more than one of these coarse policy domains. My point here is simply that these fifteen issues include a diverse sample of policy conflicts in the contemporary political landscape.

${ }^{11}$ I remove oversamples from the 2008 and 2012 ANES. Varying the minimum number of responses between three and six does not appear to substantively affect the results. A matrix of the survey items and additional details are provided in the supplementary materials (available online).

${ }^{12}$ To simplify interpretation, I present absolute values of the estimated discrimination parameters. I am also cautious to interpret changes in the latent parameters in ordinal rather than cardinal terms, as relative comparisons are more appropriate given the measurement level of the underlying scale (Ho and Quinn 2010).
} 
American National Election Studies: 1980-2016

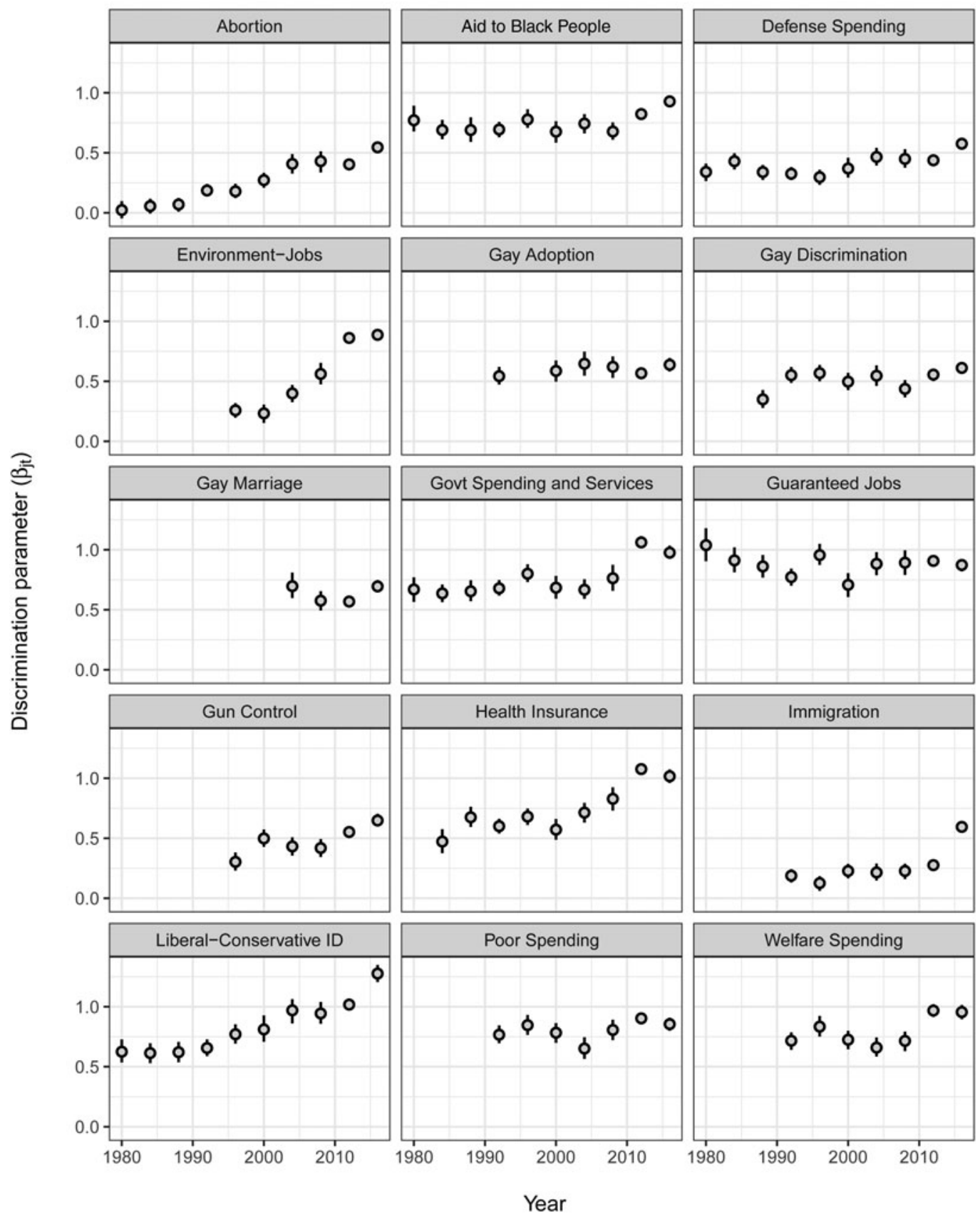

Figure 1. Issue discrimination parameters $\left(\beta_{j t}\right)$ from the Bayesian DO-IRT model. Note: Bars show 95 per cent credible intervals. Source: 1980-2016 ANES.

protection, and health insurance are particularly striking. Abortion attitudes are now about as ideologically constrained as attitudes on defense spending, while environmental protection and health insurance have discrimination parameters on a par with the traditional social welfare 
issue scales of guaranteed jobs and government spending and services. Moreover, Figure 1 shows that ideological self-identifications have become a considerably better indicator of respondents' operational policy preferences since 1980.

Figure 1 provides scant evidence that newer social/cultural policy conflicts are displacing longstanding disagreements over economic and social welfare issues. While the latent dimension has increasingly absorbed such social/cultural issues as abortion and gun control, the discrimination parameters of economic/social welfare items (that is, government spending and services, guaranteed jobs and income, government-private health insurance, federal spending on the poor, and federal spending on welfare) have all remained stable or increased over this period. Of these, health insurance attitudes have seen the most dramatic increase in constraint (with muchthough not all-of this change occurring between 2008 and 2012). ${ }^{13}$ To the extent that the government aid to black people item taps into economic preferences, the stability of its discrimination parameter since 1980 also speaks to the continued relevance of economic issues in defining ideological conflict.

Although the discrimination parameters of three items relating to LGBTQ rights (adoption, job discrimination, and same-sex marriage) do not exhibit a marked increase over this period, citizens' attitudes on these issues already fit within a unidimensional ideological structure since their introduction in the ANES. At the same time, attitudes on abortion-which throughout the 1980s had a discrimination parameter of virtually 0 -have become increasingly constrained by the ideological dimension over this period. Consequently, cultural and moral conflict in US society is well manifested in the contemporary ideological divide. Far from being relegated to a secondary dimension, Americans' social/cultural attitudes are an increasingly important component of the ideological fabric of US public opinion. Since liberal-conservative identification also taps into citizens' broad social/cultural postures (Conover and Feldman 1981; Stimson 2015), the increase of its discrimination parameter is consistent with this claim.

It is also noteworthy that respondents' immigration attitudes (that is, their desired level of immigration) become more ideologically constrained between 2012 and 2016. Immigration provides a recent example of a deeply symbolic, "easy" issue that became salient and clearly differentiated the parties in the 2016 presidential election (Reny, Collingwood, and Valenzuela 2019; Sides, Tesler, and Vavreck 2019). During this span, its discrimination parameter increases from minimal to modest, placing it in line with social/cultural controversies such as abortion, gun control, and LGBTQ rights. Moreover, as with other issues, the results show that immigration has supplemented rather than replaced other policy disputes on the ideological conflict dimension.

Finally, in addition to tracking how issue loadings evolve over time, the DO-IRT model also captures changes in the way issues divide the ideological continuum via the item difficulty parameters. These parameters represent how liberal or conservative a respondent must be to have a predicted response on a given issue, and hence shifts in what constitutes a "liberal" or "conservative" response over this period. LGBTQ rights offers a prime example of such an issue where public opinion has shifted dramatically between 1988 (when relevant questions were first introduced in the ANES) and 2016. Figure 2 shows the estimated cut points between response options for one such item concerning laws to protect gays and lesbians from job discrimination. ${ }^{14}$ The results show that a respondent in 1988 would need to be on the far-left end of the ideological dimension (with an ideal point less than -2) to be modeled as answering that they "strongly" favor such laws. The thresholds track steadily rightward in the space, such

\footnotetext{
${ }^{13}$ The supplementary materials (available online) provide an alternate way to visualize the growth in mass constraint by showing changes in predicted response probabilities on each issue by respondents at the 10th, 25th, 50th, 75th, and 90th ideal-point percentiles.

${ }^{14}$ The $y$-axis shows the latent left-right dimension recovered by the DO-IRT model, with higher values indicating more conservative positions. Issue cut points are calculated as $\left(\alpha_{j c t} / \beta_{j t}\right)$.
} 


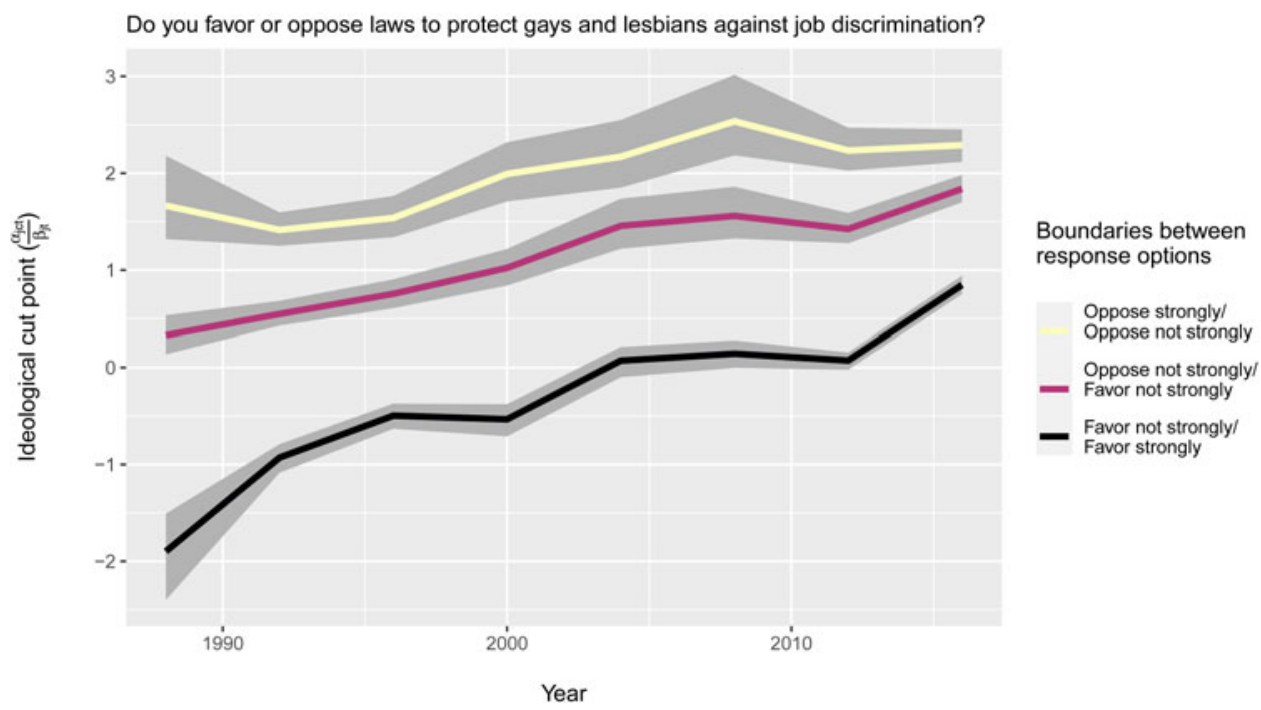

Figure 2. Cut points for gay discrimination from the Bayesian DO-IRT model. Note: Shade regions show 95 per cent credible intervals.

Source: 1988-2016 ANES.

that by 2016, all ideologically centrist and many conservative respondents are predicted to favor (either "strongly" or "not strongly") laws against gay and lesbian job discrimination. Of course, this has also been the case for political candidates and legislators, hence the need for dynamic ideal-point models. Simply put, responses to survey items like these mean different things at different times, and the changing meanings of specific policy positions appear to be identified by the DO-IRT model.

\section{Differences in Constraint by Level of Political Sophistication}

The results outlined earlier showed evidence of increased ideological constraint in the US electorate as a whole, but how do these trends vary among subsets of survey respondents? In particular, to what extent have changes in ideological constraint been conditioned by political sophistication? In this section, I modify the DO-IRT model to allow for random effects in the difficulty $\left(\alpha_{j c t}\right)$ and discrimination $\left(\beta_{j t}\right)$ parameters between three levels of political sophistication. The coding scheme for political sophistication is adopted from Lupton, Myers, and Thornton (2015): three indicators (self-reported interest in the campaign, participation in campaign activities, and interviewer assessment of respondent knowledge) are standardized and the mean is used as the sophistication score. ${ }^{15}$ Respondents are then divided into three sophistication tertiles (low, medium, and high) by year based on their score.

Figure 3 tracks changes in the issue discrimination parameters of ANES respondents by level of political sophistication. As in Figure 1, higher values indicate a stronger relationship between the issue and the latent ideological dimension. Not surprisingly, Figure 3 shows that attitudinal constraint across issues is generally higher among more politically sophisticated respondents.

\footnotetext{
${ }^{15}$ The variables from the ANES Time Series cumulative data file are VCF0310 for interest, VCF0723 for involvement, and VCF0050a for knowledge. Cronbach's $\alpha=0.63$ and Loevinger's $H=0.45$, indicating that these items form a reliable, unidimensional scale (Sijtsma and van der Ark 2017).
} 
However, on most issues, all of the political sophistication groups see meaningful increases in their discrimination parameters over this period. On policy items as varied as abortion, environment-jobs, and health insurance, the ANES 2016 respondents with low levels of political sophistication exhibit levels of ideological constraint on a par with their highly sophisticated counterparts in the 1980s and 1990s. The effects of conflict extension do not appear to be confined to the most politically engaged voters, but rather cut across the electorate and reach even citizens who have minimal interaction with the political system.

To be certain, there remains a clear gradation in the level of attitudinal constraint exhibited by high-, middle-, and low-sophistication voters. On the issue of immigration, for instance, the discrimination parameter for the least politically sophisticated respondents remained low through the 2016 election, while the discrimination parameters for moderately and (especially) highly sophisticated respondents spiked. It seems reasonable to suspect that the influence of changes in the political environment on attitudinal constraint simply take longer to make their way to the least attentive voters, though future work should investigate this conjecture.

Nonetheless, the results presented in this section substantiate a long-theorized benefit of polarization: voters-even relatively disconnected voters-are adopting better-structured political preferences in line with the ideologically constrained choice set presented to them (see, for example, American Political Science Association, 1950). Elite polarization has compelled partisan-ideological sorting among voters across levels of political sophistication by clarifying policy differences between the parties (Levendusky 2010; Zingher and Flynn 2019). My findings suggest that it has also fostered somewhat greater unidimensional ideological constraint among voters classified at low, medium, and high levels of political sophistication. Recognition of partisan differences on policy matters appears to be the most important specific mechanism driving sorting, and awareness of these distinctions has steadily increased across the electorate since the 1980s (Freeder, Lenz, and Turney 2019; Sniderman 2017). ${ }^{16}$ Indeed, when reproducing Figure 3 by instead dividing respondents based on correct/incorrect ideological placement of the parties, the results (provided in the supplementary materials, available online) show that the growth in mass ideological constraint has been nearly entirely concentrated among citizens who are able to correctly identify the relative ideological positions of the two major parties. Elite polarization has placed this task within the reach of less politically sophisticated voters.

\section{The Sources of Increased Ideological Constraint}

The previous analysis documented how mass attitudes on a wide array of policy issues have become increasingly structured along a single latent ideological dimension over the last forty years. In this section, I examine the sources of the growth of unidimensional ideological constraint over this period. In particular, I assess the extent to which the left-right dimension has incorporated core values and party identification alongside voters' policy preferences.

Past work-especially the literature on sorting in the mass electorate-shows that the linkages between ideology, partisanship, and vote choice have grown stronger over recent decades (Bafumi and Shapiro 2009; Baldassarri and Gelman 2008; Levendusky 2009). ${ }^{17}$ Less clear-but no less

\footnotetext{
${ }^{16}$ For instance, among the respondents in the analysis, 21 per cent (65 per cent) of low-sophistication (high-sophistication) respondents in 1980 correctly placed the Democratic Party to the left of the Republican Party on the seven-point liberal-conservative scale, while in 2016, these figures rose to 62 per cent ( 89 per cent) (see also Levendusky 2009).

${ }^{17}$ In particular, the present findings closely parallel those of Baldassarri and Gelman (2008), who also examine mass polarization in terms of constraint, that is, the degree of alignment between and among voters' political dispositions (especially partisanship) and their attitudes across a wide range of policy controversies. Using ANES data to estimate issue-party and issue-pair correlations between 1972 and 2004, they find stronger evidence of an increase in issue partisanship (constraint between partisanship and issue attitudes) than in issue alignment (constraint between specific issue attitudes). However, their results also indicate that the growth in issue alignment has been more pronounced among politically interested, wealthy, and partisan voters over this period.
} 
American National Election Studies: 1980-2016

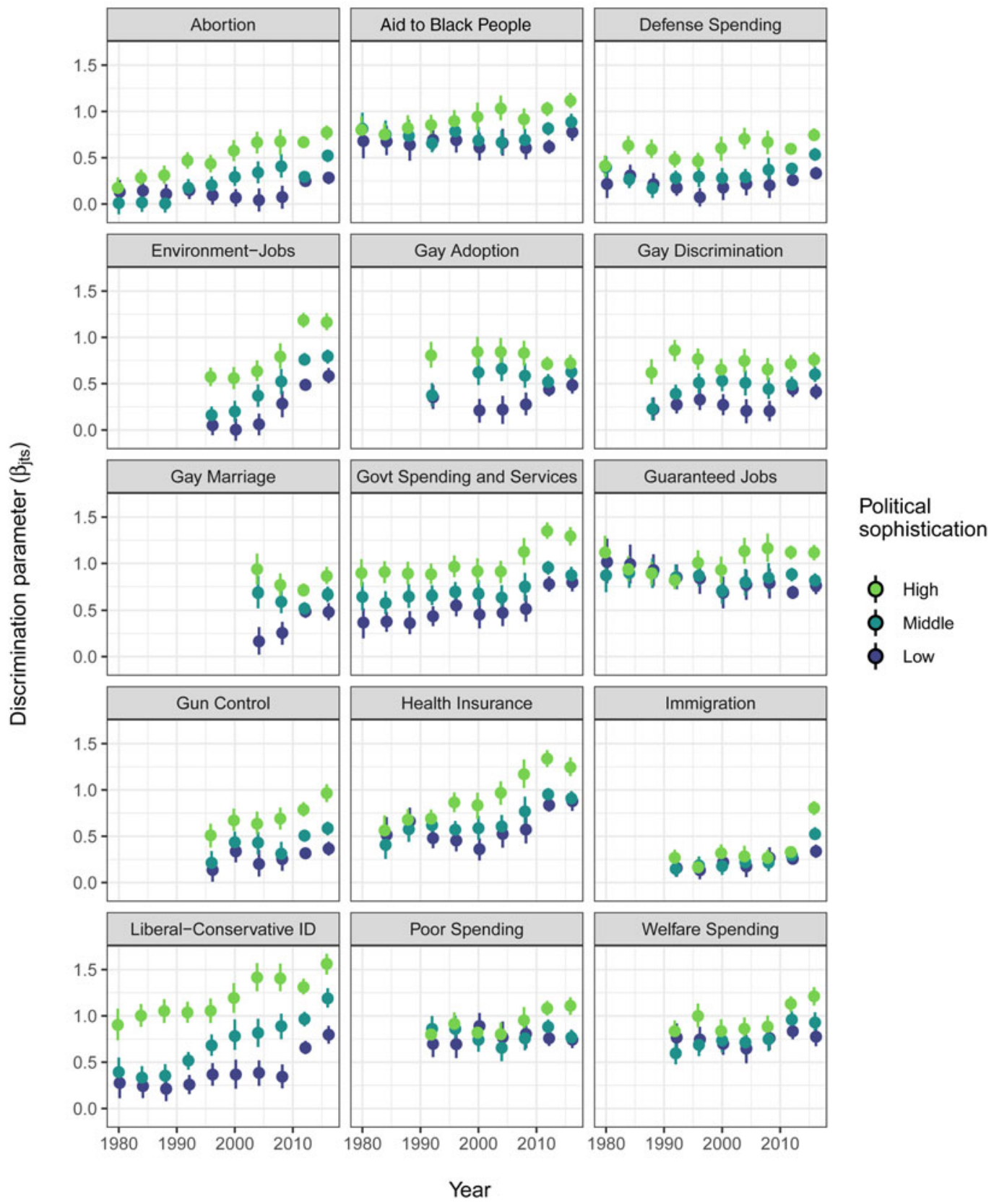

Figure 3. Issue discrimination parameters $\left(\beta_{j t s}\right)$ from the Bayesian DO-IRT model by level of political sophistication. Note: Bars show 95 per cent credible intervals. Source: 1980-2016 ANES.

consequential-is how the relationship between core value dispositions and political attitude structures has evolved in a polarized political environment. It is well established that core values influence attitudes on specific political issues and divide partisans in the contemporary mass 
electorate (Goren 2013; Jacoby 2014), but are citizens' basic value dispositions related to changes in the ideological structure of US public opinion? The theory of conflict extension leads to the expectation that the latent ideological dimension I measure in this article has increasingly encompassed core values and beliefs relating to economic and social policies over the last forty years. Stated otherwise, basic value postures toward both economic and social behavior should be increasingly connected to the primary dimension structuring competition in contemporary US politics.

I first consider this relationship by shifting to the other set of parameters estimated by the DO-IRT model: the respondent ideal points $\left(\theta_{i}\right)$ on the recovered ideological dimension. Figure 4 shows the over-time simple Pearson correlations between ANES respondents' ideological ideal points and three fundamental political dispositions: party identification, economic egalitarianism, and moral traditionalism. ${ }^{18}$ As before, I consider respondents with low, medium, and high levels of political sophistication separately.

The results closely parallel those from the previous section, which examined changes in ideological constraint by level of political sophistication. In particular, Figure 4 reveals that more politically sophisticated respondents possess more meaningful unidimensional attitude structures, in this case, holding ideological positions that are more tightly connected to partisanship and both core values. Among highly politically sophisticated respondents, correlations generally range between 0.5 and 0.7 on the egalitarianism and moral traditionalism scales, and between 0.6 and 0.8 on party identification.

However, voters' ideological, partisan, and value dispositions have become more tightly interwoven among all three political sophistication groups. Moderately politically sophisticated respondents have seen the largest increases in the correlations between their ideal points and each of these dispositions, especially on the moral traditionalism index (rising from $r=0: 18$ in 1988 to $r=0: 65$ in 2016). Indeed, by the end of this series, the correlations among moderatesophistication respondents only slightly lag those of their highly sophisticated counterparts. Moreover, as in the previous section, low-sophistication respondents in the 2010s closely resemble high-sophistication respondents during the 1980s.

Collectively, the egalitarianism and moral traditionalism value dispositions explain a slightly larger proportion of the variance in voters' ideological positions than party identification across years and political sophistication levels. Figure 5 demonstrates this by plotting $R^{2}$ values from linear regressions of the respondent ideal-point estimates $\left(\theta_{i}\right)$ on different combinations of the value and partisan dispositions. ${ }^{19}$ In all cases, the core values model provides greater explanatory power than the party identification model, though the combined model (party + core values) outperforms both. The results indicate that the growth in mass ideological constraint is not simply a product of partisan-ideological sorting; rather, core values have also come to increasingly explain voters' left-right positions. By 2016, the combined model achieves $R^{2}$ values of $0.41,0.61$, and 0.73 for low-, medium-, and high-sophistication respondents, respectively. ${ }^{20}$

Taken together, Figures 4 and 5 indicate that conflict extension in the mass electorate has not been confined to specific issue attitudes, but also encompasses core values and party identification. Consistent with the results presented in the previous section, social values (that is, moral traditionalism) have supplemented rather than displaced economic values as a correlate of mass ideology over the last forty years. Indeed, economic egalitarianism has become more strongly related to ideology during this period. These results suggest that voters have not engaged

\footnotetext{
${ }^{18}$ The analysis begins in 1988, when the core value batteries were introduced in the ANES. Party identification is measured using the traditional seven-point scale, while the core values are measured using summated indices of responses to the six-item egalitarianism and four-item moral traditionalism batteries.

${ }^{19}$ Note that the curves in Figure 5 represent actual $R^{2}$ values from the corresponding linear regressions, not marginal improvements in $R^{2}$ between the subsets of explanatory variables.

${ }^{20}$ Of course, this is a lower-bound estimate of the amount of variance explained at the ideological ideal points since it considers only the additive linear effects of core values and partisanship.
} 


\section{American National Election Studies: 1988-2016}

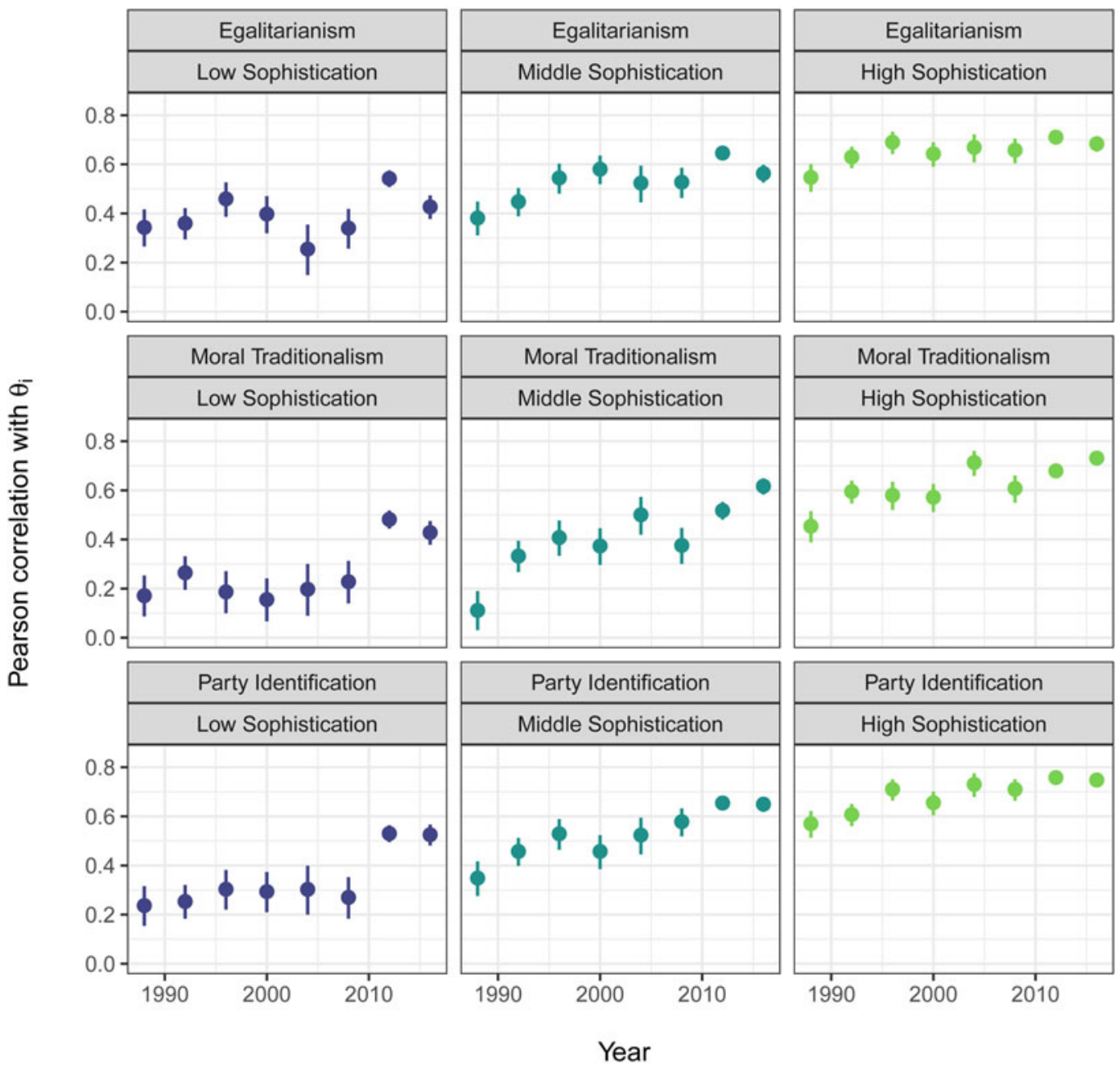

Figure 4. Correlations between respondent ideal-point estimates $\left(\theta_{i}\right)$ and core values and partisanship by level of political sophistication.

Note: Bars show 95 per cent credible intervals.

Source: 1988-2016 ANES.

in blind sorting over recent decades, but are adopting ideological positions increasingly in line with core values and partisan dispositions. As with the changes in the issue loadings documented in the previous section, the growing influence of values and party identification on ideology have occurred among voters across levels of political sophistication.

Consequently, in the contemporary US electorate, ideology has come to reflect divisions over both economic and social matters. However, it is important to emphasize that ideological divides not only encompass specific economic and social policy controversies, but also run deeper to fundamental value cleavages over private and public morality, as well as the extent to which society should promote economic equality. The results are consonant with Jacoby's $(2014,24)$ assertion that, "In the past, values were regarded as an alternative to ideology, providing organizational parsimony for political attitudes among people who did not conceptualize the world in abstract 


\section{American National Election Studies: 1988-2016}
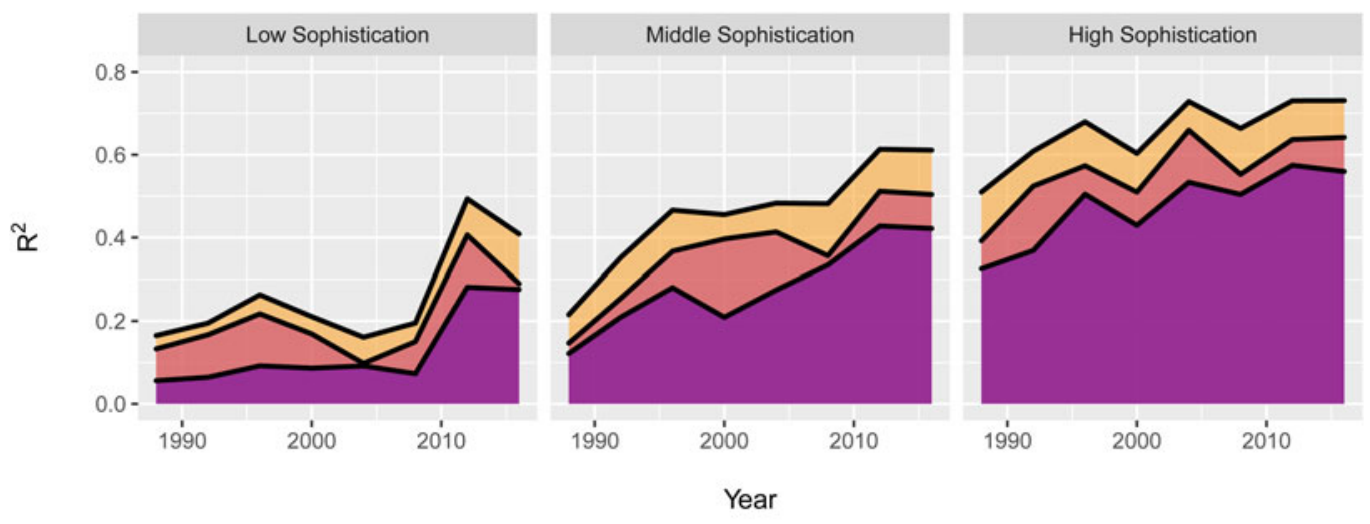

Party + Core Values

Core Values Only

Party Only

Figure 5. Fit of regression models of respondent ideal-point estimates $\left(\theta_{i}\right)$ on combinations of core values and partisanship by level of political sophistication.

Note: Core values include egalitarianism and moral traditionalism indices.

Source: 1988-2016 ANES.

terms (Feldman 1988). In contrast, the present findings suggest that value orientations actually reinforce ideological distinctions." On this front too, polarization has served to shrink the gap between politically active citizens and the remainder of the electorate (especially between moderately and highly sophisticated citizens) (Levendusky 2009, Levendusky 2010; Zingher and Flynn 2019). The results suggest that both partisanship and core values serve as gateways to ideological reasoning for voters at all levels of political sophistication.

\section{Discussion}

One of the curious things about political opinions is how often the same people line up on opposite sides of different issues. The issues themselves may have no intrinsic connection with each other.... Yet the same familiar faces can be found glaring at each other from opposite sides of the political fence, again and again.... A closer look at the arguments on both sides often shows that they are reasoning from fundamentally different premises. These different premises-often implicit—are what provide the consistency behind repeated opposition of individuals and groups on numerous, unrelated issues. (Sowell 2007, 3)

This article offers separate methodological and substantive contributions to the study of ideological constraint in the US electorate. The development of a Bayesian DO-IRT model with timevarying item parameters offers a method to measure mass ideology that accounts for changes in public opinion over time. Substantively, the application of this model to public opinion survey data collected over the last forty years provides considerable evidence substantiating the existence of mass conflict extension (Layman and Carsey 2002a, Layman and Carsey 2002b). Indeed, the results show that much of the conflict extension literature understates the degree to which citizens' policy attitudes have collapsed onto a single ideological dimension. Mass ideology is not strictly unidimensional, but the two main dimensions (economic and social/cultural) have become increasingly intertwined over the past forty years (see also Stoetzer and Zittlau 2020). The largest growth in unidimensional constraint has occurred among respondents with low and moderate levels of political sophistication, somewhat narrowing the knowledge gap in ideological thinking. 
Combustible social/cultural issues that speak to moral and religious divides have been increasingly folded into already-contentious divides over economic and social welfare policies, but this has not been the only important change to the ideological structure of US public opinion. Fundamental cleavages involving values like economic egalitarianism and moral traditionalism have also been absorbed into the same dimension. The primary ideological dimension underlying political attitudes increasingly reflects both policy and value divisions on both economic and social/cultural matters. This is an important but often overlooked aspect of political polarization: the meaning of the ideological dimension and the structure of political competition-what partisans are fighting aboutsurely shapes the nature of ideological and partisan conflict in US politics. These results indicate that polarization in the US electorate has increased in two respects: existing policy and value cleavages have calcified; and more conflicts have been absorbed into the ideological dimension.

Normatively, these findings are something of a mixed bag. On the one hand, democratic theorists and political scientists alike have long bemoaned the lack of structure in voters' policy attitudes and choice, stemming in large part from Converse's (1964) landmark essay. After all, there is widespread agreement that US political elites operate in unidimensional ideological space (see, for example, Bonica 2014; Poole and Rosenthal 2007). That voters'-especially less politically sophisticated voters'-attitudes are better mapped onto this same space means that they are also better equipped to connect their policy preferences to such political behaviors as party identification and vote choice (see also Levendusky 2010).

At the same time, the presence of reinforcing cleavages in US public opinion presents potential dangers for the health of a pluralistic democracy, with the same groups continually engaging in multiple (and often emotional) policy and value conflicts. It seems only natural that partisans would like each other less, view the other side as illegitimate, and be less amenable to compromise (Davis 2019; DellaPosta forthcoming; Iyengar and Westwood 2015; Mason 2018). Future work should (and undoubtedly will) continue to sort out the feedback processes between the policy and affective components of political polarization, as well as explore the consequences of conflict extension on more extreme varieties of affective polarization, such as political dehumanization and the rejection of democratic norms.

Changes in the structure and content of voters' ideological divisions are an essential feature of partisan conflict in contemporary US politics. In particular, the US political system has long relied on citizens who are less passionate about politics to rein in ideological conflict (Fiorina, Abrams, and Pope 2011). That this group has also experienced substantial growth in ideological constraint impedes an important obstacle to deeper polarization.

Supplementary Material. Online appendices are available at: https://doi.org/10.1017/S000712342100051X

Data Availability Statement. Replication data for this article can be found in Harvard Dataverse at: https://doi.org/10. 7910/DVN/ZURHQA

Acknowledgments. I thank Jim Adams, Ben Highton, Adrienne Hosek, Bill Jacoby, Brad Jones, Jeff Lewis, Bob Lupton, Keith Poole, Howard Rosenthal, and four anonymous reviewers for their helpful feedback and comments.

Financial Support. None

Competing Interests. None

\section{References}

Abramowitz AI and Saunders KL (1998) Ideological realignment in the U.S. electorate. Journal of Politics 60(3), 634-652. Achen CH (1975) Mass political attitudes and the survey response. American Political Science Review 69(4), $1218-1231$.

Adams J, Green J and Milazzo C (2012) Has the British public depolarized along with political elites? An American perspective on British public opinion. Comparative Political Studies 45(4), 507-530.

American Political Science Association (1950) Toward a More Responsible Two-Party System: A Report of the Committee on Political Parties of the American Political Science Association. New York, NY: Rinehart. 
Ansolabehere S, Rodden J and Snyder JM Jr (2008) The strength of issues: using multiple measures to gauge preference stability, ideological constraint, and issue voting. American Political Science Review 102(2), 215-232.

Bafumi J and Shapiro RY (2009) A new partisan voter. Journal of Politics 71(1), 1-24.

Baldassarri D and Gelman A (2008) Partisans without constraint: political polarization and trends in American public opinion. American Journal of Sociology 114(2), 408-446.

Barker DC and Tinnick JD III (2006) Competing visions of parental roles and ideological constraint. American Political Science Review 100(2), 249-263.

Bawn K et al. (2012) A theory of political parties: groups, policy demands and nominations in American politics. Perspectives on Politics 10(3), 571-597.

Berelson B (1952) Democratic theory and public opinion. Public Opinion Quarterly 16(3), 313-330.

Bonica A (2014) Mapping the ideological marketplace. American Journal of Political Science 58(2), 367-386.

Brady HE and Sniderman PM (1985) Attitude attribution: a group basis for political reasoning. American Political Science Review 79(4), 1061-1078.

Brown JR and Enos RD (forthcoming) The measurement of partisan sorting for 180 million voters. Nature Human Behaviour 5, 998-1008.

Carmines EG and Stimson JA (1980) The two faces of issue voting. American Political Science Review 74(1), 78-91.

Carmines EG and Stimson JA (1989) Issue Evolution: Race and the Transformation of American Politics. Princeton, NJ: Princeton University Press.

Carsey TM and Layman GC (2006) Changing sides or changing minds? Party identification and policy preferences in the American electorate. American Journal of Political Science 50(2), 464-477.

Caughey D and Warshaw C (2015) Dynamic estimation of latent opinion using a hierarchical group-level IRT model. Political Analysis 23(2), 197-211.

Clifford S and Jerit J (2013) How words do the work of politics: moral foundations theory and the debate over stem cell research. Journal of Politics 75(3), 659-671.

Clinton J et al. (2021) Partisan pandemic: how partisanship and public health concerns affect individuals' social mobility during COVID-19. Science Advances 7(2), 1-7.

Conover PJ and Feldman S (1981) The origins and meaning of liberal/conservative self-identifications. American Journal of Political Science 25(4), 617-645.

Converse PE (1964) The nature of belief systems in mass publics. In Apter DE (ed.), Ideology and Discontent. New York, NY: Free Press, pp. 206-261.

Davis NT (2019) Identity sorting and political compromise. American Politics Research 47(2), 391-414.

Davis NT, Klar S and Weber CR (2019) Affective consistency and sorting. Social Science Quarterly 100(6), $2477-2494$.

DellaPosta D (2020) Pluralistic collapse: the "oil spill” model of mass opinion polarization. American Sociological Review 85(3), 507-536.

Druckman JN, Peterson E and Slothuus R (2013) How elite partisan polarization affects public opinion formation. American Political Science Review 107(1), 57-79.

Enders AM and Armaly MT (2019) The differential effects of actual and perceived polarization. Political Behavior 41(3), 815-839.

Enders AM and Lupton RN (2021) Value extremity contributes to affective polarization in the US. Political Science Research and Methods 9(4), 507-536.

Endres K and Panagopoulos C (2017) Boycotts, buycotts, and political consumerism in America. Research \& Politics 4(4), 1-9.

Fariss CJ (2014) Respect for human rights has improved over time: modeling the changing standard of accountability. American Political Science Review 108(2), 297-318.

Feldman S (1988) Structure and consistency in public opinion: the role of core beliefs and values. American Journal of Political Science 32(2), 416-440.

Feldman S (2003) Values, ideology, and the structure of political attitudes. In Sears DO, Huddy L and Jervis R (eds), Oxford Handbook of Political Psychology. New York, NY: Oxford University Press, pp. 477-508.

Fiorina MP, Abrams SJ and Pope JC (2011) Culture War? The Myth of a Polarized America, 3rd edn, New York, NY: Pearson Longman.

Freeder S, Lenz GS and Turney S (2019) The importance of knowing "what goes with what": reinterpreting the evidence on policy attitude stability. Journal of Politics 81(1), 274-290.

Freeze M and Montgomery JM (2016) Static stability and evolving constraint: preference stability and ideological structure in the mass public. American Politics Research 44(3), 415-447.

Goren P (2013) On Voter Competence. Series in Political Psychology. New York, NY: Oxford University Press.

Goren P, Smith B and Motta $\mathbf{M}$ (forthcoming) Human values and sophistication interaction theory. Political Behavior. https://doi.org/10.1007/s11109-020-09611-8

Habermas J (1996) Between Facts and Norms: Contributions to a Discourse Theory of Law and Democracy. Cambridge, MA: MIT Press. 
Hamill R, Lodge M and Blake F (1985) The breadth, depth, and utility of class, partisan, and ideological schemata. American Journal of Political Science 29(4), 850-870.

Hare C (2021) Replication data for: Constrained citizens? Ideological structure and conflict extension in the American electorate 1980-2016, https://doi.org/10.7910/DVN/ZURHQA, Harvard Dataverse, V1, UNF:6:eMb/r2ALAqzCsszB9AcPmg $==[$ fileUNF $]$

Hetherington MJ (2009) Review article: putting polarization in perspective. British Journal of Political Science 39(2), 413-448.

Hetherington MJ and Weiler JD (2009) Authoritarianism and Polarization in American Politics. Cambridge: Cambridge University Press.

Highton B and Kam CD (2011) The long-term dynamics of partisanship and issue orientations. Journal of Politics 73(1), 202-215.

Hill SJ and Tausanovitch C (2015) A disconnect in representation? Comparison of trends in congressional and public polarization. Journal of Politics 77(4), 1058-1075.

Hinich MJ and Munger MC (1994) Ideology and the Theory of Political Choice. Ann Arbor, MI: University of Michigan Press.

Ho DE and Quinn KM (2010) How not to lie with judicial votes: misconceptions, measurement, and models. California Law Review 98(3), 813-876.

Huber GA and Malhotra N (2017) Political homophily in social relationships: evidence from online dating behavior. Journal of Politics 79(1), 269-283.

Hunter JD (1991) Culture Wars: The Struggle to Define America. New York, NY: Basic Books.

Iyengar S and Westwood SJ (2015) Fear and loathing across party lines: new evidence on group polarization. American Journal of Political Science 59(3), 690-707.

Jackson JE (1983) The systematic beliefs of the mass public: estimating policy preferences with survey data. Journal of Politics 45(4), 840-865.

Jacoby WG (1991) Ideological identification and issue attitudes. American Journal of Political Science 35(1), 178-205.

Jacoby WG (2014) Is there a culture war? Conflicting value structures in American public opinion. American Political Science Review 108(4), 754-771.

Jessee SA (2012) Ideology and Spatial Voting in American Elections. Cambridge: Cambridge University Press.

Kinder DR and Kalmoe NP (2017) Neither Liberal nor Conservative: Ideological Innocence in the American Public. Chicago, IL: University of Chicago Press.

Layman GC and Carsey TM (2002a) Party polarization and "conflict extension" in the American electorate. American Journal of Political Science 46(4), 786-802.

Layman GC and Carsey TM (2002b) Party polarization and party structuring of policy attitudes: a comparison of three NES panel studies. Political Behavior 24(3), 199-236.

Layman GC et al. (2010) Activists and conflict extension in American party politics. American Political Science Review 104 (2), 324-346.

Levendusky M (2009) The Partisan Sort: How Liberals Became Democrats and Conservatives Became Republicans. Chicago, IL: University of Chicago Press.

Levendusky M (2010) Clearer cues, more consistent voters: a benefit of elite polarization. Political Behavior 32(1), 111-131.

Lorde A (1984) Learning from the 60s. In Apter DE (ed.), Sister Outsider: Essays and Speeches, Trumansburg, NY: Crossing, pp. 134-144.

Lupton RN, Myers WM and Thornton JR (2015) Political sophistication and the dimensionality of elite and mass attitudes, 1980-2004. Journal of Politics 77(2), 368-380.

Lupton RN, Smallpage SM and Enders AM (2020) Values and political predispositions in the age of polarization: examining the relationship between partisanship and ideology in the United States, 1988-2012. British Journal of Political Science 50 (1), 241-260.

Martin AD and Quinn KM (2002) Dynamic ideal point estimation via Markov chain Monte Carlo for the U.S. Supreme Court, 1953-1999. Political Analysis 10(2), 134-153.

Mason L (2018) Uncivil Agreement: How Politics Became Our Identity. Chicago, IL: University of Chicago Press.

Miller G and Schofield N (2003) Activists and partisan realignment in the United States. American Political Science Review 97(2), 245-260.

Nie NH, Verba S and Petrocik JR (1979) The Changing American Voter. Cambridge: Harvard University Press.

Noel H (2013) Political Ideologies and Political Parties in America. Cambridge: Cambridge University Press.

O'Brian NA (2020) Before Reagan: the development of abortion's partisan divide. Perspectives on Politics 18(4), $1031-1047$.

Orr LV and Huber GA (2020) The policy basis of measured partisan animosity in the United States. American Journal of Political Science 64(3), 569-586.

Palfrey TR and Poole KT (1987) The relationship between information, ideology, and voting behavior. American Journal of Political Science 31(3), 511-530.

Poole KT and Rosenthal H (2007) Ideology and Congress. New Brunswick, NJ: Transaction. 
Popkin SL (2006) The factual basis of "belief systems": a reassessment. Critical Review 18(1-3), 233-254.

Quinn KM (2004) Bayesian factor analysis for mixed ordinal and continuous responses. Political Analysis 12(4), 338-353.

Reny TT, Collingwood L and Valenzuela AA (2019) Vote switching in the 2016 election: how racial and immigration attitudes, not economics, explain shifts in white voting. Public Opinion Quarterly 83(1), 91-113.

Reuning K, Kenwick MR and Fariss CJ (2019) Exploring the dynamics of latent variable models. Political Analysis 27(4), 503-517.

Rogowski JC and Sutherland JL (2016) How ideology fuels affective polarization. Political Behavior 38(2), $485-508$.

Samejima F (1997) Graded response model. In van der Linden WJ and Hambleton RK (eds), Handbook of Modern Item Response Theory. New York: Springer, pp. 85-100.

Schickler E (2016) Racial Realignment: The Transformation of American Liberalism, 1032-1965. Princeton, NJ: Princeton University Press.

Shor B and McCarty N (2011) The ideological mapping of American legislatures. American Political Science Review 105(3), 530-551.

Shor B and Rogowski JC (2018) Ideology and the US congressional vote. Political Science Research and Methods 6(2), 323-341.

Sides J, Tesler M and Vavreck L (2019) Identity Crisis: The 2016 Presidential Campaign and the Battle for the Meaning of America. Princeton, NJ: Princeton University Press.

Sijtsma K and van der Ark LA (2017) A tutorial on how to do a Mokken scale analysis on your test and questionnaire data. British Journal of Mathematical and Statistical Psychology 70(1), 137-158.

Sniderman PM (2017) The Democratic Faith: Essays on Democratic Citizenship. New Haven, CT: Yale University Press.

Sniderman PM and Bullock J (2004) A consistency theory of public opinion and political choice: the hypothesis of menu dependence. In Saris WE and Sniderman PM (eds), Studies in Public Opinion: Attitudes, Nonattitudes, Measurement Error, and Change. Princeton, NJ: Princeton University Press, pp. 337-357.

Sowell T (2007) A Conflict of Visions: Ideological Origins of Political Struggles, rev. edn, New York, NY: Basic Books.

Stimson JA (1975) Belief systems: constraint, complexity, and the 1972 election. American Journal of Political Science 19(3), 393-417.

Stimson JA (2015) Tides of Consent: How Public Opinion Shapes American Politics, 2nd edn, Cambridge: Cambridge University Press.

Stoetzer LF (2019) A matter of representation: spatial voting and inconsistent policy preferences. British Journal of Political Science 49(3), 941-956.

Stoetzer LF and Zittlau S (2020) Vote choice and the nonseparability of economic and social issues. Public Opinion Quarterly 84(1), 158-170.

Stoker L and Jennings MK (2008) Of time and the development of partisan polarization. American Journal of Political Science 52(3), 619-635.

Sundquist JL (1983) Dynamics of the Party System: Alignment and Realignment of Political Parties in the United States, rev. edn, Washington, DC: Brookings Institution Press.

Thorisdottir H et al. (2007) Psychological needs and values underlying left-right political orientation: cross-national evidence from Eastern and Western Europe. Public Opinion Quarterly 71(2), 175-203.

Treier S and Hillygus DS (2009) The nature of political ideology in the contemporary electorate. Public Opinion Quarterly 73(4), 679-703.

Zhou X (2019) Hierarchical item response models for analyzing public opinion. Political Analysis 27(4), 481-502.

Zingher JN and Flynn ME (2019) Does polarization affect even the inattentive? Assessing the relationship between political sophistication, policy orientations, and elite cues. Electoral Studies 57, 131-142.

Cite this article: Hare C (2022). Constrained Citizens? Ideological Structure and Conflict Extension in the US Electorate, 1980-2016. British Journal of Political Science 52, 1602-1621. https://doi.org/10.1017/S000712342100051X 